\title{
Effect of immunoglobulin G concentration in dairy cow colostrum and calf blood serum on Cryptosporidium spp. invasion in calves
}

\author{
Alīna Derbakova ${ }^{1}$, Maksims Zolovs $^{2}$, Dace Keidāne ${ }^{1}$ and Žanete Šteingolde ${ }^{3}$
}

1. Institute of Food and Environmental Hygiene, Faculty of Veterinary Medicine, Latvia University of Life Sciences and Technologies, Kr. Helmana Street 8, Jelgava, Latvia, LV-3004; 2. Department of Biosystematics, Institute of Life Sciences and Technology, Daugavpils University, Parades Street 1a, Daugavpils, Latvia, LV-5401; 3. Animal Disease Diagnostic Laboratory, Institute of Food Safety, Animal Health and Environment "BIOR," Lejupes Street 3, Riga, Latvia, LV-1076. Corresponding author: Maksims Zolovs, e-mail: maksims.zolovs@du.Iv

Co-authors: AD: alina.derbakova@gmail.com,DK: dacekeidane@gmail.com, ZS: zanete.steingolde@bior.Iv Received: 09-10-2019, Accepted: 18-12-2019, Published online: 24-01-2020

doi: www.doi.org/10.14202/vetworld.2020.165-169 How to cite this article: Derbakova A, Zolovs M, Keidāne $D$, Šteingolde Z (2020) Effect of immunoglobulin G concentration in dairy cow colostrum and calf blood serum on Cryptosporidium spp. invasion in calves, Veterinary World, 13(1): 165-169.

\begin{abstract}
Aim: The research aimed to test the association between the level of immunoglobulin $\mathrm{G}$ (IgG) in bovine colostrum and calf blood serum and to evaluate its relation to Cryptosporidium spp. invasion in calves.

Materials and Methods: Fresh colostrum and fecal specimens from cows ( $n=114)$ as well as blood and fecal specimens from newborn calves $(n=114)$ were collected in the dairy cattle farm. Investigated calves were separated from their mothers directly after birth and received $2 \mathrm{~L}$ of colostrum in two separate feedings within the first $24 \mathrm{~h}$. Blood samples were taken from calves at the age of 2 days. Coprological samples were taken from calves at the age of 1,10 , and 15 days. Both colostrum and fecal samples from cows were taken on the $1^{\text {st }}$ day after calf birth. Rectal fecal samples were collected separately from each calf and cow into plastic bags. The collected calf serum samples and bovine colostrum samples were tested for bovine IgG by competitive enzyme-linked immunosorbent assay kit bovine Ig. To record oocysts of Cryptosporidium spp. in feces, the flotation method was used. Binomial logistic regression was performed to ascertain the effects of IgG in bovine colostrum and calf blood serum on the likelihood of Cryptosporidium spp. infection in calves.
\end{abstract}

Results: The concentration of $\mathrm{IgG}$ in bovine colostrum was higher $(70.7 \pm 26.6 \mathrm{~g} / \mathrm{L}$, mean \pm standard deviation $)$ than that in calf blood serum $(13.2 \pm 6.1 \mathrm{~g} / \mathrm{L})$; the statistically significant difference was $57.4 \mathrm{~g} / \mathrm{L}$ (95\% confidence interval, 52.4-62.4), $\mathrm{t}(124.872)=22.536, \mathrm{p}<0.001$. Mann-Whitney's U-test showed a significant difference between samples collected on days 10 and 15 of the experiment $(\mathrm{U}=1944, \mathrm{z}=2.330, \mathrm{p}=0.020)$. The higher number of oocysts in calf feces was recorded on day 15 (median=6.5) compared to day 10 (median=4). The prevalence of calf infection from days 10 to 15 increased from 26.3 to $45.6 \%$ and was at least 3 times higher than in cows. A statistically significant positive correlation was recorded between IgG concentration of cow colostrum and calf blood serum ( $\mathrm{r}(114)=0.414, \mathrm{p}=0.001)$, whereas a correlation between the concentration of IgG and the intensity of Cryptosporidium spp. infection was not recorded $(\mathrm{p}>0.05)$. The logistic regression model was not statistically significant $\left(\chi^{2}(2)=0.013, \mathrm{p}=0.99\right.$ (10 days) and $\chi^{2}(2)=0.100, \mathrm{p}=0.95$ (15 days)).

Conclusion: Mother passive transfer of immunity to the offspring through colostrum does not influence the susceptibility of calves to Cryptosporidium infestation.

Keywords: calves, Cryptosporidium, dairy cows, immunoglobulins.

\section{Introduction}

Cryptosporidiosis is a frequent disease in neonatal dairy and beef cattle calves. Cryptosporidium spp. cause varying degrees of naturally occurring diarrhea in farm animals. For example, Cryptosporidium parvum is an economically important parasite that causes neonatal diarrhea in calves, lambs, and goat kids. Ignoring the presence of this parasite in farms may result in increased costs for the labor involved in supporting these calves during cryptosporidiosis or even in the death of infected calves [1]. The importance

Copyright: Derbakova, et al. Open Access. This article is distributed under the terms of the Creative Commons Attribution 4.0 International License (http://creativecommons.org/licenses/ by/4.0/), which permits unrestricted use, distribution, and reproduction in any medium, provided you give appropriate credit to the original author(s) and the source, provide a link to the Creative Commons license, and indicate if changes were made. The Creative Commons Public Domain Dedication waiver (http:// creativecommons.org/publicdomain/zero/1.0/) applies to the data made available in this article, unless otherwise stated. of Cryptosporidium spp. is also highlighted by their zoonotic and anthroponotic nature and by the numerous paths of parasite transmission: Water, food, clothes, and footwear. Cryptosporidium is a reason for the common cause of acute diarrhea in immunocompetent individuals [2] and recognized as a major waterborne parasite worldwide [3].

The parasites commonly act in concert with other enteropathogens to produce intestinal injury and diarrhea [4]. Colostrum is the first source of newborn food that not only feeds the animal but also provides necessary components for protection. Therefore, receiving adequate colostrum immediately after birth is needed to help prevent the invasion of opportunistic pathogens which can worsen or compound the severity of disease in calves with cryptosporidiosis. Such compounds necessary are immunoglobulins (Ig), which are glycoproteins that specifically recognize and bind to antigens present on pathogens. As Ig have a high 
degree of specificity, they assist in the destruction of specific pathogens. In animals with the first and second placenta types, such as cows, and Ig are not transferred from maternal blood to the fetus. However, calves receive Ig through passive transfer from colostrum [5]. There are several classes of Ig, including $\operatorname{IgA}, \operatorname{IgD}, \operatorname{IgE}, \operatorname{IgG}$, and $\operatorname{IgM}[6]$; however, most of them are present in colostrum at low concentrations. Of these, IgG are of particular interest because they are the primary Ig found in bovine colostrum and milk and play the main role in the development of humoral immunity [7]. The concentration of IgG in colostrum may reach up to $50-100 \mathrm{mg} / \mathrm{ml}$, and by passive transfer, they provide effective prevention or treatment of several human or animal diseases caused by pathogens (Yersinia enterocolitica, Campylobacter jejuni, Escherichia coli, Klebsiella pneumoniae, Serratia marcescens, Salmonella typhimurium, Staphylococcus, Streptococcus, Cryptosporidium, etc.) [8]. As Ig can prevent the adhesion of pathogens to intestinal epithelial cells, they act as the primal protection against most of the potential gastrointestinal pathogens. For example, IgG by adhesion to invasive stages of Cryptosporidium may play a role in preventing invasion into host cells.

The concentration and effect of IgG on calf health have repeatedly been studied [9-14]. For example, Johnsen et al. [9] attempted to develop a less invasive and easy method to measure $\operatorname{IgG}$ concentration, whereas Aydogdu and Guzelbektes [10] compared colostrum composition between primiparous and multiparous dairy cows. However, only a few investigations of Ig focused on parasitic infections $[15,16]$. The effects of cryptosporidiosis on calf growth in the long term have not yet been shown, but occurring diarrhea may be costly for farmers due to the loss of income from lower carcass weights. Petry et al. [17] noted that the protective role of antibodies is questionable because high titers of parasite-specific IgG can be found in AIDS patients with chronic cryptosporidiosis.

In light of this, this study aimed to test the association between the level of IgG in bovine colostrum and the calf's blood serum and to evaluate its relation to Cryptosporidium spp. invasion in calves. We expected to find an immunological link between cow immunity and the passive transfer of immunity to calves, related to Cryptosporidium spp. infection.

\section{Materials and Methods}

\section{Ethical approval}

All procedures performed in studies involving animals were in accordance with the ethical standards. The study was approved by the Animal Welfare and Ethical Council of the Faculty of Veterinary Medicine, Latvia, University of Life Sciences and Technologies, and complied with current laws in Latvia.

\section{Sample collection}

Fresh colostrum and fecal specimens from cows $(\mathrm{n}=114)$ as well as blood and fecal specimens from newborn calves $(\mathrm{n}=114)$ were collected in the dairy cattle farm between December 2018 and March 2019. Investigated calves were separated from their mothers directly after birth and received $2 \mathrm{~L}$ of colostrum in two separate feedings within the first $24 \mathrm{~h}$. Blood samples were taken from 2-day-old calves. Coprological samples were taken from calves at the age of 1, 10, and 15 days. Both colostrum and fecal samples from cows were taken on the $1^{\text {st }}$ day after calf birth. Rectal fecal samples were collected separately from each calf and cow into plastic bags, marked, and kept in a refrigerator at $4^{\circ} \mathrm{C}$ before examination. If the number of feces was too small (especially in the $1^{\text {st }}$ days of the calves' life), native smears were made. Before laboratory investigation, blood samples were centrifuged to obtain blood serum and stored at $-80^{\circ} \mathrm{C}$. The colostrum was stored at the same temperature. During the research, no animals were subjected to unnecessary pain or distress.

\section{Serological techniques}

The collected calf serum samples and bovine colostrum samples were tested for bovine IgG, using the competitive enzyme-linked immunosorbent assay (ELISA) kit bovine Ig (Bio - X Diagnostics, Belgium) in the Institute of Food Safety, Animal Health, and Environment "BIOR," Serology Division, Latvia. Samples were tested according to the manufacturer's instructions, and the calibration curve for calf serum and bovine colostrum was established. Calf serum samples were diluted $1 / 100$, and colostrum samples were diluted $1 / 1000$. In the dilution microplate wells, $100 \mu \mathrm{L}$ of the calibration curve dilutions and diluted samples were transferred, and diluted conjugate was added to each well, mixed, and $100 \mu \mathrm{L}$ of the content were transferred to the kit's microplate wells. The microplate was incubated at $+21 \pm 3^{\circ} \mathrm{C}$ for $1 \mathrm{~h}$. Subsequently, the microplate was rinsed 3 times with a washing solution, and $100 \mu \mathrm{L}$ of chromatogen solution were added to each followed by incubation at $+21 \pm 3^{\circ} \mathrm{C}$ for $10 \mathrm{~min}$ in the dark. The reaction was stopped by adding $50 \mu \mathrm{L}$ of stop solution to each well. The optical density of the investigated samples was determined using a monochromatic ELISA reader (Thermo Scientific Multiskan FC) with a 450-nm filter. The Ig concentrations were calculated using "Four Parameter Logistic Curve" online data analysis tool, MyAssays Ltd., 10 ${ }^{\text {th }}$ March 2017, http://www. myassays.com/four-parameter-logistic-curve.assay.

\section{Coprological examination}

All coprological samples were exanimated on the collection day. Laboratory examinations were made in the Laboratory of Parasitology, Institute of Food and Environmental Hygiene, Faculty of Veterinary Medicine, Latvia University of Agriculture. To record oocysts of Cryptosporidium spp. in feces, the flotation method was used according to Fujino et al. [18]. Slides were stained using the modified Ziehl-Neelsen method [19]. 


\section{Statistical analysis}

To test the difference between the means of two groups, we used the independent-samples t-test or the Mann-Whitney U-test. The assumption of normality was tested by Shapiro-Wilk's test and assumption of homogeneity of variances by Levene's test. To determine the strength and direction of a linear relationship between two continuous variables, we used Pearson's correlation. Binomial logistic regression was performed to ascertain the effects of IgG in bovine colostrum and calf's blood serum on the likelihood of Cryptosporidium spp. infection in calves. The linearity of the continuous variables with respect to the logit of the dependent variable was assessed through the Box and Tidwell procedure [20]. Bonferroni correction was applied using three terms in the model, resulting in statistical significance being accepted when $p<0.016667$ [21]. Based on this assessment, all continuous independent variables were found to be linearly related to the logit of the dependent variable.

\section{Results}

A Welch t-test was run to determine if there were differences in the concentrations of $\operatorname{IgG}$ between bovine colostrum and calf's blood serum due to the assumption of homogeneity of variances being violated, as assessed by Levene's test for equality of variances $(F=127.433 \mathrm{p}<0.001)$. Concentrations of $\mathrm{IgG}$ for bovine colostrum and calf blood serum were normally distributed $(p>0.05)$. The concentration of $\mathrm{IgG}$ in bovine colostrum was higher $(70.7 \pm 26.6 \mathrm{~g} / \mathrm{L}$, mean \pm standard deviation) than that in calf blood serum $(13.2 \pm 6.1 \mathrm{~g} / \mathrm{L})$; the statistically significant difference was $57.4 \mathrm{~g} / \mathrm{L}$ (95\% confidence interval, 52.4 to 62.4$), \mathrm{t}(124.872)=22.536, \mathrm{p}<0.001$. The number of Cryptosporidium spp. oocysts in feces was not normally distributed $(\mathrm{p}<0.05)$. In the $1^{\text {st }}$ day of the experiment, the prevalence of Cryptosporidium spp. was $0 \%$. Mann-Whitney U-test showed a significant difference between samples collected on days 10 and 15 of the experiment; $U=1944, z=2.330, p=0.020$. The higher number of oocysts in calf feces was recorded on day 15 (median=6.5) compared to day $10($ median $=4)$ of the experiment. The prevalence of calf infection from days 10 to 15 increased from 26.3 to $45.6 \%$ and was at least 3 times higher than in cows.

A statistically significant positive correlation was recorded between concentrations of IgG in cow colostrum and calf blood serum ( $\mathrm{r}(114)=0.414, \mathrm{p}=0.001)$, whereas a correlation between concentrations of $\mathrm{IgG}$ and intensity of Cryptosporidium spp. infection was not recorded ( $p>0.05$; Figure- 1$)$. The logistic regression model was not statistically significant; $\chi^{2}(2)=0.013, p=0.99 \quad(10$ days $)$ and $\chi^{2}(2)=0.100$, $\mathrm{p}=0.95$ ( 15 days), indicating the lack of relationships between the concentration of $\operatorname{IgG}$ (in bovine colostrum and calf blood serum) and calf infection with Cryptosporidium spp.

\section{Discussion}

The main results showed that calves are born with lower IgG concentrations in the blood compared to cow colostrum. The concentration of $\operatorname{IgG}$ in calf blood is directly related to feeding with cow colostrum. Although there is an immunological link between immunity of the mother and passive transfer of immunity to the offspring [22], this study showed the lack of a relationship between concentrations of IgG (both mother and offspring) and Cryptosporidium spp. infection. Surprisingly, there was an increase in the infection prevalence of Cryptosporidium spp. because colostrum and milk contain not only IgG but also a range of other components such as neutrophils, macrophages, lymphocytes, antimicrobial factors, and other molecules that provide energy for an effective immune response [23-25].

The immune responses to Cryptosporidium species infection involve both innate and adaptive immunity. Numerous studies have described the role of $\mathrm{T}$ and $\mathrm{B}$ cells, intestinal epithelial cells, interferon-gamma and natural killer cells, nitric oxide, antimicrobial peptides, prostaglandins, mannose-binding lectin, cytokines, chemokines, dendritic cells, and

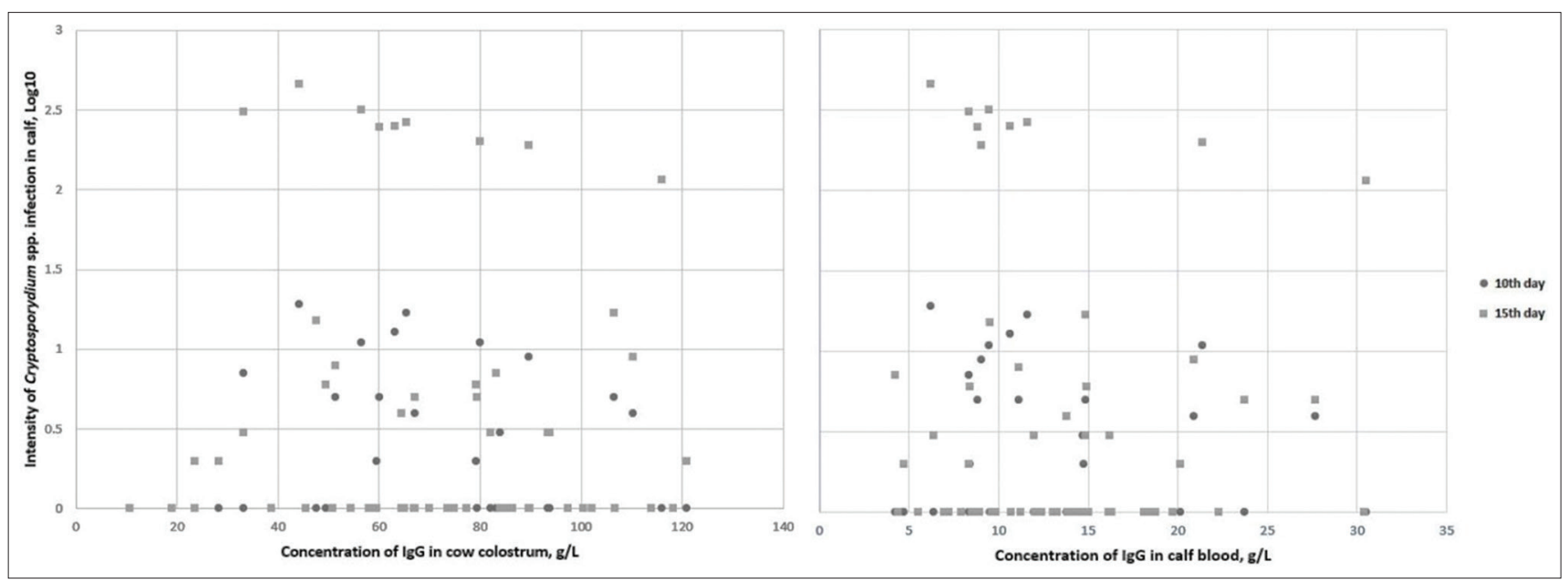

Figure-1: Association between the concentration of immunoglobulin $\mathrm{G}$ and intensity of Cryptosporidium spp. infection in calves. 
macrophages in the formation of immune responses to Cryptosporidium spp.; a summary of these studies may be found in the reviews of Leitcha and Heb [26] and Vanathy et al. [27]. Our study indicates that innate and adaptive immunity play more significant roles in immune responses to Cryptosporidium species than mother passive transfers of immunity to the offspring. Furthermore, Siachos et al. [28] suggest that passive transfer of Ig is not protective against cryptosporidiosis. However, Ajjampur et al. [29] have studied antibody responses to specific antigens (gp40 and gp15) before and after the first episode of symptomatic cryptosporidiosis in children and found significant increases of $\operatorname{IgG}$ levels in response to Cryptosporidium antigens. Similar results have been obtained by Allison et al. [30], who studied antibody responses to the immunodominant gp 15 antigen from Cryptosporidium hominis and C. parvum. They also recorded that IgM response occurs immediately after an acute infection and levels decrease within weeks, whereas IgG responses are slower to appear but persist for a longer period.

Previous studies of Cryptosporidium prevalence in the USA [31] and China [32] coincide with our findings that calves have a higher prevalence of infection than cows. For example, Santín et al. [33] concluded that the prevalence of Cryptosporidium species is age-related between pre-weaned and post-weaned calves. Harp et al. [34] demonstrated that initial exposure of $C$. parvum to calves (from birth to 3 months) and their recovery renders calves resistant to further challenge with the parasite. Most likely, these findings indirectly highlight the significance of adaptive immunity to Cryptosporidium infection. However, Gong et al. [32] have indicated that Cryptosporidium species/subtypes vary among the different age groups of cattle, suggesting that infection with a single species of Cryptosporidium and further recovery do not guarantee the inability of cryptosporidiosis caused by other species. Thomson et al. [35] have suggested that the ability of the parasite to infect the gut is linked to changes in the gut microflora during animal maturation, although there are no experimental trials demonstrating this in cattle.

\section{Conclusion}

We found that mother passive transfer of immunity to the offspring through colostrum does not influence the susceptibility of calves to Cryptosporidium infestation.

\section{Authors' Contributions}

$\mathrm{AD}$ developed the study design and carried out the experiment. ZS performed calf serum and bovine colostrum sample serological examination. DK supervised the research process. MZ performed the statistical analysis of all data. AD and MZ wrote the manuscript with input from all authors. All authors read and approved the final manuscript.

\section{Acknowledgments}

This study was supported by Daugavpils University, Latvia through scientific grant No. 14-89/3.

\section{Competing Interests}

The authors declare that they have no competing interests.

\section{Publisher's Note}

Veterinary World remains neutral with regard to jurisdictional claims in published institutional affiliation.

\section{References}

1. Rahman, R.N.R., Isa, M.L.M. and Yuso, A.M. (2017) A review of Cryptosporidium spp. infection in livestock. J. Teknol., 79(6): 99-109.

2. Wanyiri, J.W., Kanyi, H., Maina, S., Wang, D.E., Steen, A., Ngugi, P., Kamau, T., Waithera, T., O’Connor, R., Gachuhi, K., Wamae, C.N., Mwamburi, M. and Ward, H.D. (2014) Cryptosporidiosis in HIV/AIDS patients in Kenya: Clinical features, epidemiology, molecular characterization and antibody responses. Am. J. Trop. Med. Hyg., 91(2): 319-328.

3. Thompson, R.C.A., Koh, H.W. and Clode L.P. (2016) Cryptosporidium what is it? Food Waterborne Parasitol., 4: 54-61.

4. Hawash, Y.A., Ismail, K.A. and Almehmadi, M. (2017) High frequency of enteric protozoan, viral, and bacterial potential pathogens in community-acquired acute diarrheal episodes: Evidence based on results of luminex gastrointestinal pathogen panel assay. Korean J. Parasitol., 55(5): 513-521.

5. Gomez, D.E. and Chamorro, F.M. (2017) The importance of colostrum for dairy calves. Rev. Colomb. Cienc. Pecu., 30(Suppl.): 241-244.

6. Kaskous, S. and Fadlelmoula, A. (2015) Immunoglobulin in colostrum and health of newborn calves. Sci. J. Rev., 4(12): 242-249.

7. McGrath, A.B., Fox, F.P., McSweeney, L.H.P. and Kelly L.A. (2016) Composition and properties of bovine colostrum: A review. Dairy Sci. Technol., 96(2): 133-158.

8. Ulfman, L.H., Leusen, J.H.W., Savelkoul, H.F.J., Warner, J.O. and Joost van Neerven, R.J. (2018) Effect of bovine immunoglobulins on immune function, allergy, and infection. Front. Nutr., 5: 52

9. Johnsen, F.J., Chincarini, M., Sogstad, M.A., Solverod, L., Vatne, M., Mejdell, M.C. and Hanninen, L. (2019) Salivary IgG levels in neonatal calves and its association to serum IgG: An observational pilot study. Tran. Anmi. Sci., 3(1): 589-593.

10. Aydogdu, U. and Guzelbektes, H. (2018) Effect of colostrum composition on passive calf immunity in primiparous and multiparous dairy cows. Vet. Med., 63(1): 1-11.

11. Meganck, V., Hoflack, G. and Opsomer, G. (2014) Advances in prevention and therapy of neonatal dairy calf diarrhoea: A systematical review with emphasis on colostrum management and fluid therapy. Acta Vet. Scand., 56(1): 75.

12. Gelsinger, S.L. and Heinrichs, A.J. (2017) A short review: The immune system of the dairy calf and the importance of colostrum IgG. J. Dairy Vet. Anim. Res., 5(3): 104-107.

13. Conneely, M., Berry, D.P., Murphy, J.P., Lorenz, I., Doherty, M.L. and Kennedy, E. (2014) Effect of feeding colostrum at different volumes and subsequent number of transition milk feeds on the serum immunoglobulin G concentration and health status of dairy calves. J. Dairy Sci., 97(11): 6991-7000.

14. Verweij, J.J., Koets, A.P. and Eisenberg, S.W.F (2014) Effect of continuous milking on immunoglobulin concentrations in bovine colostrum. Vet. Immunol. Immunopathol., 160(3-4): 225-229.

15. Tzipori, S., Roberton, D. and Chapman, C. (1986) 
Remission of diarrhoea due to cryptosporidiosis in an immunodeficient child treated with hyperimmune bovine colostrum. Br. Med. J., 293(6557): 1276-1277.

16. Shield, J., Melville, C., Novelli, V., Anderson, G., Scheimberg, I., Gibb, D. and Milla, P. (1993) Bovine colostrum immunoglobulin concentrate for cryptosporidiosis in AIDS. Arch. Dis. Child., 69(4): 451-453.

17. Petry, F., Jakobi, V. and Tessema, T.S. (2010) Host immune response to Cryptosporidium parvum infection. Exp. Parasitol., 126(3): 304-309.

18. Fujino, T., Matsuo, T., Okada, M. and Matsui, T. (2016) Detection of a small number of Cryptosporidium parvum oocysts by sugar flotation and sugar centrifugation methods. J. Vet. Med. Sci., 68(11): 1191-1193.

19. Henriksen, S.A. and Pohlenz, J.F.L. (1981) Staining of cryptosporidia by a modified Ziehl-Neelsen. Acta Vet. Scand., 22(3-4): 594-596.

20. Box, G.E.P. and Tidwell, P.W. (1962) Transformation of the independent variables. Technometrics, 4(4): 531-550.

21. Tabachnick, B.G. and Fidell, L.S. (2014) Using multivariate statistics. $6^{\text {th }}$ ed. Pearson, Essex, UK.

22. Hurley, W.L. (2003) Immunoglobulins of the Mammary Secretions. Advanced Dairy Chemistry: Proteins. $3^{\text {rd }}$ ed. Kluwer Academic/Plenum Publishers; New York, USA.

23. Pakkanen, R. and Aalto, J. (1997) Growth factors and antimicrobial factors of bovine colostrum. Int. Dairy J., 7(5): 285-297.

24. Playford, R.J., Macdonald, C.E. and Johnson, W.S. (2000) Colostrum and milk-derived peptide growth factors for the treatment of gastrointestinal disorders. Am. J. Clin. Nutr., 72(1): 5-14

25. Blum, J.W. (2006) Nutritional physiology of neonatal calves. J. Anim. Physiol. Anim. Nutr., 90(1-2): 1-11.

26. Leitcha, G.J. and Heb, Q. (2011) Cryptosporidiosis-an overview. J. Biomed. Res., 25(1): 1-16.

27. Vanathy, K., Parija, S.C., Mandal, J., Hamide, A. and Krishnamurthy, S. (2017) Cryptosporidiosis: A mini-review. Trop. Parasitol., 7(2): 72-80.

28. Siachos, N., Sougaris, S., Kritsepi-Konstantinou, M.,
Kiosis, E., Papadopoulos, E., Kalaitzakis, E., Valergakis,G.E. and Panousis, N. (2017) Association of passive transfer of immunoglobulins and hematologic analytes with Cryptosporidium spp. Infection in Holstein calves. Revue Méd. Vét., 168(4-6): 108-115.

29. Ajjampur, S.S.R., Sarkar, R., Allison, G., Banda, K., Kane, A., Muliyil, J., Naumova, E., Ward, H. and Kang, G. (2011) Serum IgG response to Cryptosporidium immunodominant antigen gp15 and polymorphic antigen gp40 in children with cryptosporidiosis in South India. Clin. Vaccine Immunol., 18(4): 663-639.

30. Allison, G.M., Rogers, K.A., Borad, A., Ahmed, S., Karim, M.M., Kane, A.V., Hibberd, P.L., Naumova E.N., Calderwood, S.B., Ryan, E.T., Khan, W.A. and Ward H.D. (2011) Antibody responses to the immunodominant Cryptosporidium gp15 antigen and gp15 polymorphisms in a case-control study of cryptosporidiosis in children in Bangladesh. Am. J. Trop. Med. Hyg., 85(1): 97-104.

31. Lemeteil, D., Roussel, F., Favennec, L., Ballet, J.J. and Brasseur, P. (1993) Assessment of candidate anticryptosporidial agents in an immunosuppressed rat model. J. Infect. Dis., 167(3): 766-768.

32. Gong, C., Cao, X., Deng, L., Li, W., Huang, X., Lan, J., Xiao, Q., Zhong, Z., Feng, F., Zhang, Y., Wang, W., Guo, P., Wu, K. and Peng, G. (2017) Epidemiology of Cryptosporidium infection in cattle in China: A review. Parasite, 24(5): 1.

33. Santín, M., Trout, J.M., Xiao, L., Zhou, L., Greiner, E. and Fayer, R. (2004) Prevalence and age-related variation of Cryptosporidium species and genotypes in dairy calves. Vet. Parasitol., 122(2): 103-117.

34. Harp, J.A., Woodmansee, D.B. and Moon H.W. (1990) Resistance of calves to Cryptosporidium parvum: Effects of age and previous exposure. Infect. Immunol., 58(7): 2237-2240.

35. Thomson, S., Hamilton, C.A., Hope, J.C., Katzer, F., Mabbott, N.A., Morrison, L.J. and Innes, E.A. (2017) Bovine cryptosporidiosis: Impact, host-parasite interaction and control strategies. Vet. Res., 48(1): 42. 